\title{
PALAEONTOLOGY
}

\section{ON EXTINCTION}

\author{
WILLIAM SARJEANT. Department of Geological Sciences, University of \\ Saskatchewan, Saskatoon, SK
}

Around 65 million years ago, or so the story goes, an extraterrestrial object hit our earth. That impact wrought havoc upon the animals and plants of that time, in particular wiping out the group then dominant on land - the dinosaurs. It is a colourful, dramatic concept. For many people - yes, even many scientists - it has become an article of faith, so firmly accepted as to be no longer questioned.

Yes, there are good reasons to believe that there was an extraterrestrial "event" at that time. Geophysical results have produced the image of a large crater at Chicxulub, in Mexico's Yucatan Peninsula. This is considered to result from the impact of an asteroid, a large meteorite or, just possibly, a comet. Moreover, beneath the waters of the North Atlantic Ocean and widely elsewhere, the sediments at the Cretaceous-Tertiary boundary are unusually rich in iridium, an element that is normally quite rare. The iridium layer is so widespread that it is now being used to define the boundary between two geological eras, the Cretaceous and the Tertiary.

The question, though, is whether this impact did indeed trigger a worldwide extinction - of the dinosaurs and of the other creatures that were supposedly its victims. By Late Cretaceous times, the world was a populous place, with a rich vegetation in which the flowering plants were becoming predominant and with a whole array of animals other than the dinosaurs. There were crocodiles in abundance, some living wholly on land; there were lizards and snakes in quantity; most of the modern groups of birds and insects were already present; and the mammals, which had for so long been tiny creatures living in the shadow of the dinosaurs, were becoming bigger and already, it seems, competing with them for food.

Well before that "boundary event," there had already been significant changes. The pterodactyls, once the kings of the Mesozoic skies, had already succumbed to competition from the birds. Only a handful of big scavengers, typified by the jetfighter-sized Quetzalcoatlus, were still surviving. In the seas the coilshelled ammonites and the belemnites - creatures having a bullet-shaped internal "guard," much like the cuttlefish bone that budgies chew - were in deep decline. The ammonites faded out well before the end of the Cretaceous, whereas a few belemnites actually lived on past the "event." The plesiosaurs and mosasaurs, the marine reptiles which had fed on these two groups, were gone, their extinction hastened by increasing competition from the sharks. In contrast, the marine turtles, protected by their shells, swam on happily through the "event" and onward to the present day. The fishes, whether living in the seas or 
in rivers and lakes, were equally unaffected. So too was a primitive crocodile-like group called the champsosaurs, which might have seemed fit candidates for oblivion.

Yes, some species and even genera from the groups listed above did become extinct at about that time. However, these extinctions were minor, occurring at a rate readily accounted for by the competition and the changing relations of land and seas - in other words, at a quite normal rate. Neither were there major extinctions among the land plants nor the marine plankton. Yes, one small group of zooplankton did fade out, but the other groups showed no signs of decimation.

So, when considering this supposed "mass extinction" at the time of the presumed impact, we are left with the dinosaurs. Well, what about them? Weren't they a flourishing group and didn't they suffer a worldwide simultaneous wiping-out?

The answer to those questions is "No" and "We don't know." The dinosaurs, after being abundant and diverse for 125 million years, had begun to decline in variety about fifteen million years earlier - a long time earlier, longer than the entire span of man's life on earth. By the end of Cretaceous times only a few types were left, notably the ceratopsians (the horned herbivores) and the carnosaurs (the bipedal predators that preyed on them). Most other types of dinosaurs may have already faded out.

I write "may" because, in honest, we do not know when the dinosaurs became extinct. We have evidence only from a very circumscribed region - the northern Great Plains of the United States and Canada. From other parts of the world, there is as yet no information.
To confidently assume that, because an extinction happened in that time in one region, it happened worldwide at the same time, is manifestly absurd. At that same time, the marsupials (the pouched mammals) disappeared from the North American fossil record, yet they remain numerous in South America and Australasia, right through to the present day. One of them, the opossum, has even spread back to Canada!

Moreover, certain dinosaurs would surely have been well suited to life in tropical jungles. That is an environment so inimical to the processes of fossilization that we know almost nothing of what lived in it, before, during or after the time of the dinosaurs. Is it coincidence that, when reports have come of living dinosaurs, it has always been from tropical jungles?

What other evidence is there for a "mass extinction" at about the time of that supposed extraterrestrial impact? Well, there is indication from fossil plants that certain plant communities were destroyed - and guess where? Yes, you have it - in the northern Great Plains. Farther north in Canada and in other regions of the world, nothing similar seems to have happened. Moreover, even in that region the plant communities recovered fully in less than ten thousand years - in geological terms, a very swift recovery and scarcely suggesting a planet-wide devastation!

Study of the sediments beneath the North Atlantic Ocean has also revealed a hiatus, a time when the sediments were barren of microfossils. Again, though it was a brief interval, the micro-organisms were soon back. If devastation had been worldwide, where did they come from so swiftly? 
Well then, let's put it all together. Yes, there are convincing indications that, 65 million years ago, the earth may have suffered the impact of some extraterrestrial body. The iridium layer, found so widely across the globe, may have been a product of that impact (though some geochemists believe it had a volcanic origin). However, that layer is nowhere found resting upon a concentration of fossils of any kind, let alone dinosaur bones!

Indeed, the evidence from fossils does not indicate a worldwide biological cataclysm. There was no "mass extinction"; most groups of organisms survived from the Cretaceous to Tertiary, quite unaffected. The dinosaurs, already in decline, may have been wiped out in North America by the short-term environmental effects of that impact. Elsewhere in the world, though, we cannot say when they became extinct, for we have no evidence.

Editor's Note: This article was originally printed in the Ottawa Citizen.

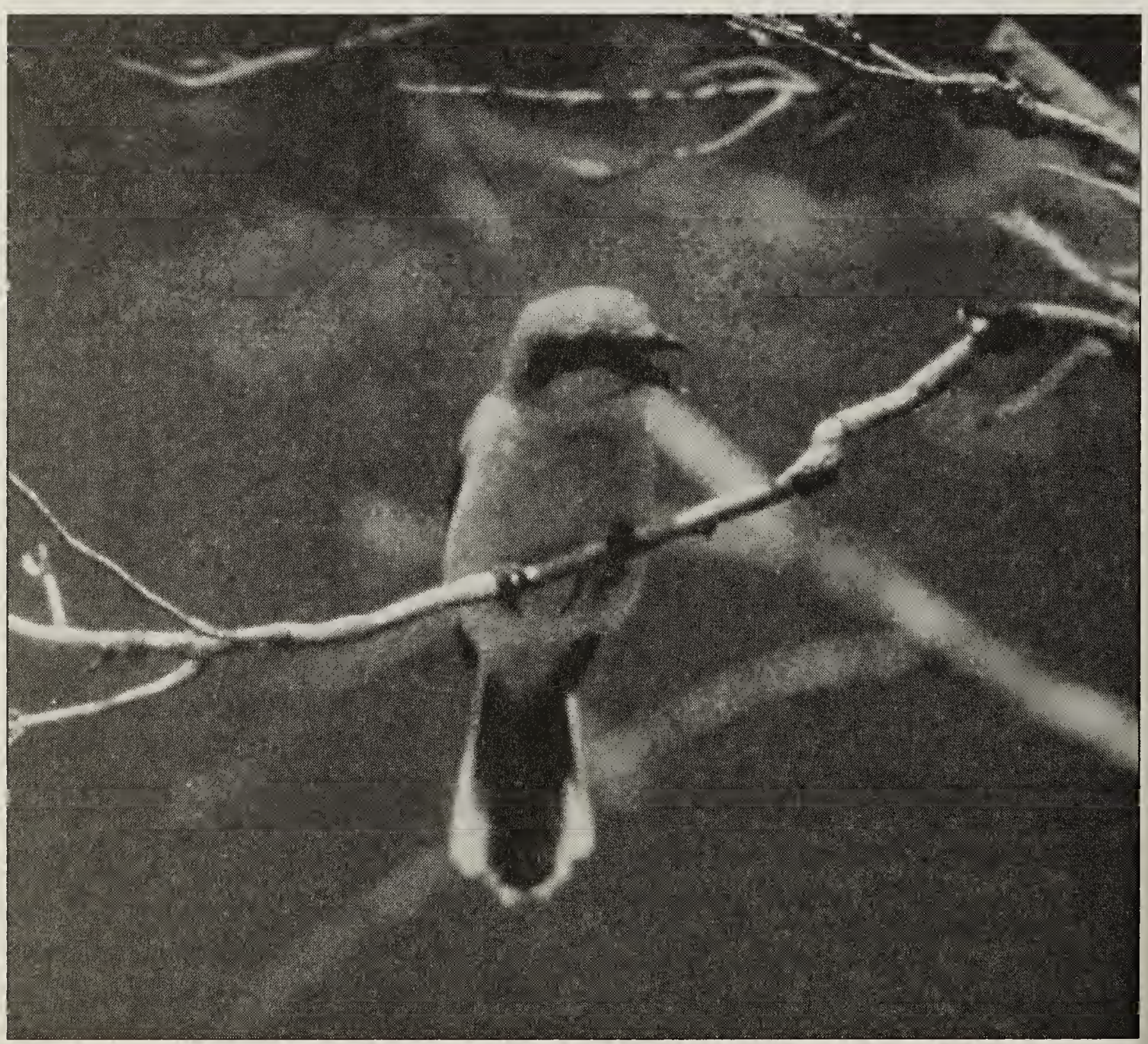

